\title{
Rhinosporidium granuloma of the conjunctiva with scleral ectasia
}

\author{
P. A. LAMBA, K. N. SHUKLA, AND M. GANAPATHY \\ Department of Ophthalmology, Jawaharlal Institute of Post-graduate Medical Education and \\ Research, Pondicherry 6, India
}

Ocular lesions due to Rhinosporidium seeberi are not common in India. The affection is predominantly one of the mucous membranes of the nose and nasopharynx, but occasionally other structures, such as the conjunctiva, lacrimal sac, lids, etc., may be affected (Kuriakose, I963; Karunaratne, I964a, b). The infection is usually limited to the surface epithelium, but in rare cases it becomes systemic (Agrawal, Sharma, and Shrivastava, I959) and the parasite can then be found in any part of the body.

The present paper presents a case of Rhinosporidium granuloma of the conjunctiva with ectasia of the sclera probably of the same aetiology. This is the second recorded case of scleral involvement in rhinosporidiosis in the world literature.

\section{Case report}

A young male office worker aged 27 years came to the ophthalmic out-patient department of JIPMER Hospital complaining of irritation and fleshy growth in the left eye for the last 2 years. He had also observed a bluish painless swelling near the same site for 20 days. There was no history of injury, and no past history of excision of the swelling was available.

\section{Ocular examination}

The cornea, anterior chamber, iris, and pupil of the left eye were normal. About $16 \mathrm{~mm}$. below and temporal to the limbus, partially concealed by the lower lid, there was a bluish, circular cystic swelling (Fig. I) bulging from the sclera. The swelling measured $10 \mathrm{~mm}$. in diameter and was covered by the conjunctiva. The cyst did not appear to be fixed to the underlying sclera. Transillumination showed that it contained clear fluid, and the base had a bluish hue on examination in the slit-lamp beam.
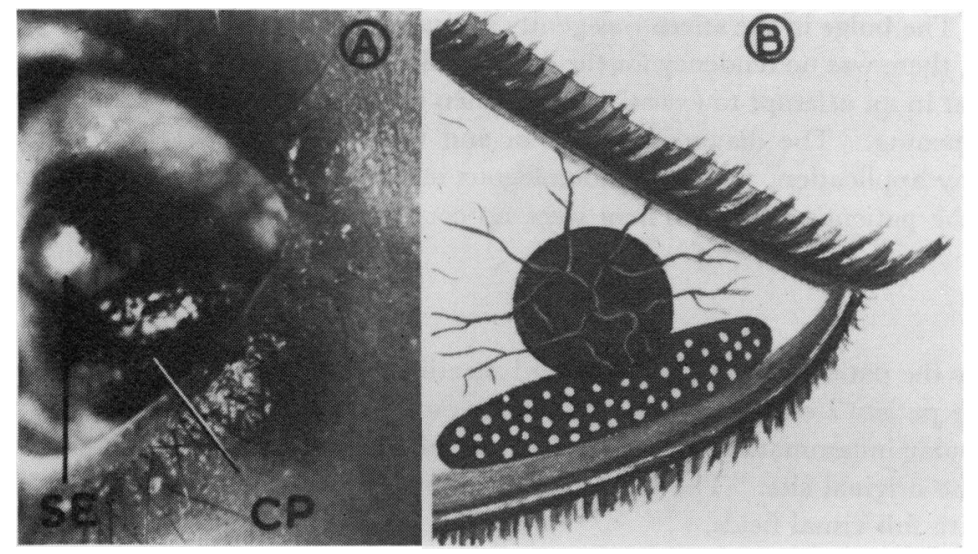

FIG. I (A) Conjunctival polyp (CP) and scleral ectasia $(S E)$. The patient was looking upwards and inwards

FIG. I (B) Diagrammatic representation of area involved 
Adjacent to this swelling, occupying the temporal part of the lower fornix, there was a papillomatous lesion with a broad base lying 3-4 mm. above the inferior fornix. The polyp was fleshy with greyish-white granular spots scattered over the surface, and bled at the slightest trauma. The patient's visual acuity was $6 / 6$ with $+\mathrm{I} .5 \mathrm{D}$ cyl., axis $90^{\circ}$. The intraocular pressure was normal (18.5 mm. Hg with $5.5 \mathrm{~g}$. weight). Ophthalmoscopy revealed that the optic disc and retina were normal with no evidence of elevation, degeneration, or hole formation (special care was taken to search for any fundus lesion opposite to the external scleral lesion).

The right eye was normal.

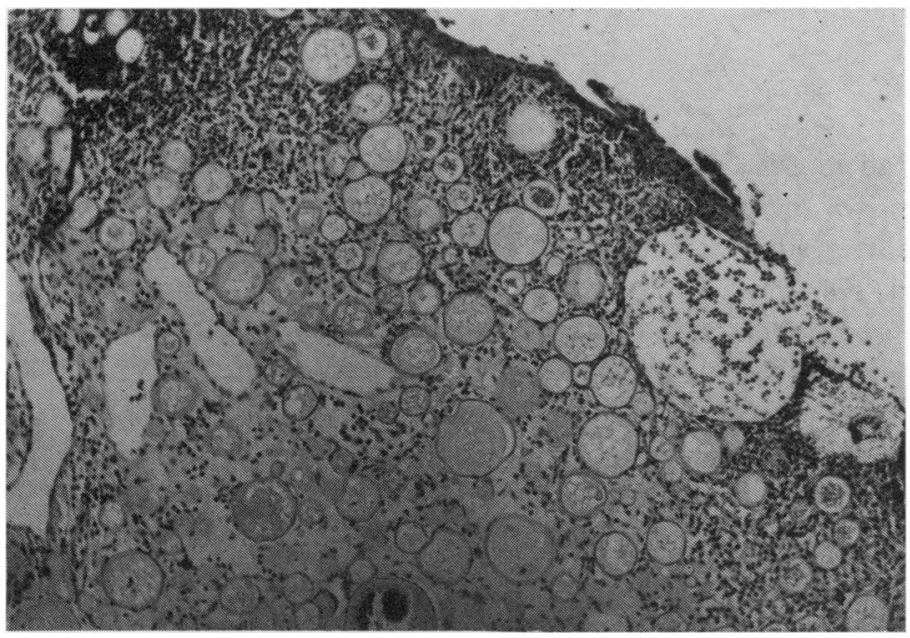

FIG. 2 Biopsy from conjunctival polyp, showing multiple sporangia in subepithelial layers. Haematoxylin and eosin. $\times 40$

\section{Investigations}

The routine haematological investigations gave normal results. Stools showed no ova or cysts. $X$ ray of the chest showed no evidence of intrathoracic suppuration. A conjunctival biopsy from the polyp showed the characteristic lesion of rhinosporidiosis (Fig. 2). A number of sporangia of various sizes were seen in the oedematous subepithelial tissue. The larger ones containing a number of sporangia burst on the surface and the surrounding tissue showed granulomatous reaction with giant cells and mononuclear cells.

\section{Treatment}

The conjunctival polyp was widely excised from its base by one of us (P.A.L.), and the bleeding vessels were cauterized. To expose the sclera, the conjunctiva and Tenon's capsule were incised with scissors. The bulge in the sclera was gently aspirated with a 23-gauge needle. After watching for ro minutes, there was no tendency for the cystic swelling to fill up. A small nick was made in the thin scleral coat in an attempt to excise the cyst when the underlying choroid was observed bulging through the opening. The diagnosis of ectasia and thinning of the scleral coat was established. After diathermy application, preserved homologous sclera ( $13 \mathrm{~mm}$. in diameter) was grafted over the defect in the patient's sclera. There were no complications and the conjunctival wound was closed.

Result

Postoperatively the patient showed no untoward reaction to the grafted tissue and the graft was well retained. The patient's condition was satisfactory on discharge after 2 weeks with no evidence of infection or ocular inflammation (Fig. 3). He was followed for 12 weeks and showed no evidence of ectasia at the original site. The visual acuity remained at the preoperative level. The retina was normal with full visual fields. 


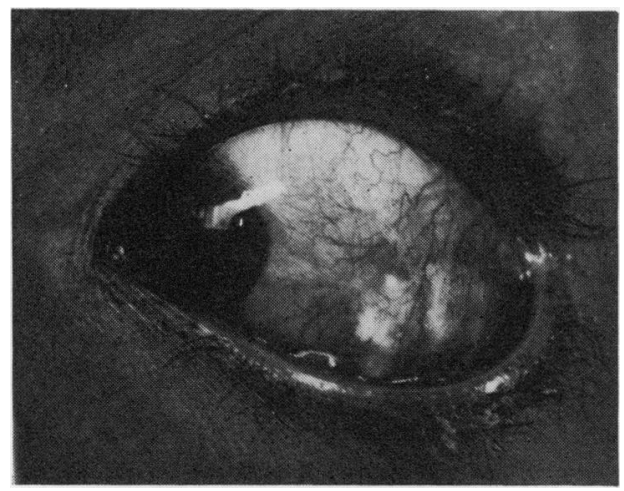

FIG. 3 Postoperative appearance after 12 weeks

\section{Discussion}

Mycotic infections of the eye are more often recognized in recent years as our knowledge of the various mycoses increases. Rhinosporidiosis is endemic in India and Ceylon, but sporadic cases of infection of the eye have been reported from other countries (Karunaratne, 1964a). The mode of infection is an intricate question, since all attempts to isolate the fungus or to produce the lesions in experimental animals have been fruitless. The published reports on the disease by workers in India, notably Allen and Dave (1936), Mandlik (1937), and Bhaskara Reddi (1954), suggest that contact with infected persons or infected water or soil may spread the disease. Males are affected more often than females in the ratio $9:$ I (Karunaratne, I964b).

\section{Site of lesions (Table)}

In most reported cases the lesions appeared in the nose and nasopharynx, ocular lesions coming next in frequency. The Table shows the frequency of involvement of various sites based on the analysis of 93 cases reported from India since rgoo. Involvement of the sclera in a circumscribed scleral staphyloma was reported in only one case (Kuriakose, 1963). In our patient the scleral lesion simulated a staphyloma, but it was actually an ectasia due to scleral thinning, probably of similar aetiology to the conjunctival polyp. Both these patients retained 6/6 visual acuity, though the scleral ectasia was expected to rupture at any time and cause the loss of the eye.

Table Involvement of various sites in 93 cases of oculosporidiosis

\begin{tabular}{|c|c|c|}
\hline Site & No. & Per cent. \\
\hline Conjunctiva & 31 & 33 \\
\hline Lacrimal sac & 36 & 39 \\
\hline Canaliculus & 1 & I \\
\hline Lid & 8 & 9 \\
\hline Sclera & I & I \\
\hline Not recorded & 16 & 17 \\
\hline Total & 93 & IOO \\
\hline
\end{tabular}

The diagnosis of the condition is usually based on clinical and histopathological findings. The lesions are essentially chronic granulomata with characteristic sporangia. In an unstained wet preparation, which shows the sporangia, special staining with Alcian blue demonstrated the Rhinosporidia as brilliant blue circles (Narayana Rao, I963). 
The conjunctival polyp should be widely excised under surface anaesthesia, but even so recurrences are common. The repair of the scleral ectasia posed the problem of $\stackrel{\partial}{.}$ perforation and loss of the eye. The idea of using a preserved homologous scleral graft $\underset{\vec{D}}{\vec{D}}$ for repair was derived from the increased use of such grafts in retinal detachment surgery (Wilson, 1964) and in cases of scleromalacia perforans. In the present case, the recipient ocular tissue has shown good tolerance of the preserved scleral graft for 12 weeks with no evidence of infection.

\section{Summary}

A second case of Rhinosporidium granuloma of the conjunctiva with scleral ectasia is reported. The scleral defect was repaired with a preserved human scleral graft with satisfactory results.

Our thanks are due to Dr. K. Chandra, M.D., Professor of Pathology, JIPMER, for the histopathological report. We are also grateful to Dr. M. Balasubramanyan, M.D., Principal of the Jawaharlal Institute of Postgraduate Medical Education and Research, Pondicherry, for permission to publish this article.

\section{References}

Agrawal, S., Sharma, K. D., and shrivastava, J. B. (i959) A.M.A. Arch. Derm., 80, 22 ALlEN, F. R. W. K., and DAVE, M. L. (1936) Indian med. Gaz., 71, 376

BHASKARA REDDI, D. (1954) Antiseptic, 51, 702

KURIakose, E. T. (1963) Brit. J. Ophthal., 47, 346

Karunaratne, w. A. E. (1964a) "Rhinosporidiosis in Man". Athlone Press, University of London (I964b) Idem, p. 64

MANDLIK, G. S. (1937) Indian med. Gaz., 72, I43

NARAYANA RaO, s. (1963) Indian J. Path. Bact., 6, I 2 I

Wilson, F. M. (1964) Arch. Ophthal. (Chicago), 72, 2 I 2 


\section{Notes}

\section{North of England Ophthalmological Society}

\section{P. F. Hay Prize, 197 I}

The P. J. Hay prize will be awarded for a paper on a subject in ophthalmology. The successful candidate will receive a sum of money and an engraved plaque. Three copies of the paper should be submitted to the Honorary Secretary, Mr. R. Ivor T. Lloyd, 2, Walmer Villas, Bradford, BD8 ${ }_{7}$ ET, Yorkshire. Closing date June 30, 197 I.

\section{Ophthalmological Society of South Africa Congress, March, I97I}

The Ophthalmological Society of South Africa will hold a Congress in Hermanus, Cape, from March I I to I4, I97 I. There will be Symposia on the cornea, glaucoma, and the posterior segment, and also free papers. Further information may be obtained from the Congress Secretary:

Dr. A. C. Neethling, 5o6 Medipark, Foreshore, Cape Town, South Africa.

\section{Wills Eye Hospital and Research Institute, Philadelphia} Course on Glaucoma, April 7-9, I97I

The Glaucoma Service of the Wills Eye Hospital, affiliated with Temple University Health Sciences Center, is offering a 3-day course (limited to thirty members) on "The Management of Patients with Glaucoma", on April 7 to 9, 1971. The tuition fee of \$150 covers tuition, luncheon, and a concert by the Philadelphia Orchestra. Inquiries should be addressed to G. L. Spaeth, M.D., Director, Glaucoma Service, Wills Eye Hospital, Philadelphia, Pa. 19130, U.S.A.

\section{Irish Ophthalmological Society}

\section{Montgomery Lecture, 197 I}

The Irish Ophthalmological Society will meet in Dublin on April 29 and 30, 1971. The Montgomery Lecture will be delivered at the Royal College of Surgeons in Ireland on the afternoon of April 29, by Mr. L. P. Jameson-Evans, F.R.G.S. (Birmingham).

\section{Pan-hellenic Ophthalmological Congress}

Rhodes, May 28-30, I97I

The V Pan-hellenic Ophthalmological Congress will be held in Rhodes from May 28-30, I97I. The main subject for discussion is "Modern aspects of the vascular diseases of the retina".

For further information write to the Secretariat of the V Pan-hellenic Ophthalmological Congress, c/o Hellenic Ophthalmological Society, Elefteriou Venizelou 26A, Athens-135, Greece.

\section{William Mackenzie Medal, I97 I}

Prof. Stephen M. Drance, of the University of British Columbia, has been awarded the William MacKenzie Medal for 197 I for his researches on the optic nerve.

\section{Corrigendum}

The claim of the authors of the article on "Rhinosporidium granuloma of the conjunctiva with scleral ectasia", which appeared last year in this journal (Brit. J. Ophthal., 1970, 54, 565), that theirs is the second case in the world literature is not correct. We have a letter from Dr. P. N. Srinivasa Rao pointing out that he described such a case in the $\mathcal{F}$. All-India ophthal. Soc. (1969), r7, 59. 